\title{
Habitus as foregrounded history: theorising affect in the social formation of embodied practice
}

\begin{abstract}
This paper builds upon a tradition of feminist critical engagements with Bourdieu (Adkins and Skeggs, 2004; Skeggs, 2011; Reay 2015), developing the concept of 'foregrounded history' as a way to conceptualise the temporal and affective in processes of habitus formation. Through analysis of affects 'produced through the social encounter' (Skeggs and Wood, 2012: 68) within everyday childhoods on a British council estate, the paper explores habitus as histories both embodied and felt in the present. Drawing upon ethnographic research conducted within the interrelated fields of the Primary School and the Community Centre, this paper considers processes of distinction (Bourdieu, 1984), disagreement (Rancière, 2004) and resistance in the formation of classed positionings on The Estate.
\end{abstract}

Keywords: habitus, affect, social class, temporality

\section{Introduction}

This paper explores the formation of classed habitus as affect. Drawing upon ethnographic research of everyday childhoods on The Estate, the paper explores habitus as histories both embodied and felt in the present, through analysis of affects produced within 'the social encounter' (Skeggs and Wood, 2012: 68).

The paper builds upon a tradition of feminist critical engagements with Bourdieu (Adkins and Skeggs, 2004; Skeggs, 2011; Reay 2015), developing the concept of 'foregrounded history' as a way to conceptualise the temporal and affective in processes of 'making through marking' (Skeggs, 2004: 12). Located within a post-structural ontology (Hall, 1997; Butler, 2004; Nayak, 2011), the research 
suggests that being on The Estate does not produce a stable 'working-class' habitus. Rather, habitus is a sense of self foregrounded in visceral moments of everyday encounter which occur when one is 'inplace'. Engaging with Skeggs' critique that Bourdieu's analysis is of the making of the 'subject of value' (2011: 501), I explore the formation of what may be positioned as devalued 'working-class' habitus through processes of distinction (Bourdieu, 1984), disagreement (Rancière, 2004) and resistance that constitute everyday life on The Estate. I draw upon everyday encounters of children 'in-place' in order to explore the formation of a classed habitus on The Estate. The paper draws upon data collected at two key sites of my ethnography, the Community Centre and the Primary School, exploring the formation of habitus as a sense of self produced through differential positionings within interrelated fields.

\section{Histories and geographies of The Estate}

This paper is founded upon ethnographic research on a council estate, located on the outskirts of a city in Britain. Through an attention to the material and social conditions which produce and legitimate knowledges of these people and this place, the research explores the becoming of class. As such, this work is produced in conversation with class theory; inspired by Bourdieu's linking of objective structures to subjective experience (Bourdieu, 1977; 1980; 1983) and feminist reflexive writings of the affective in classed beings (Walkerdine, 2010; Lucey, 2010; Skeggs, 2011; Skeggs and Wood, 2012).

Following Hanley's argument that 'class is built into the physical landscape of the country' (Hanley, 2007: 18), housing policy not only physically locates classed groups; it socially produces their affective relationships. The physical locating of classed groups within estates, therefore, cannot be disconnected from the social locating this entails. By making explicit the processes through which one comes to be on The Estate, Hanley makes visible unequal access to neoliberal formations of 
precarious citizenship. That is to say, The Estate is a place where one is housed, that this is a process beyond control, unstable and unpredictable.

The Estate of this research is positioned at the edge of the city, situated within a valley, it is visually and physically contained. This physical dislocation of The Estate produces a social distancing whereby the 'proximate stranger' (Bhabha, 1996) is imagined through repeated cultural representations, creating and consolidating myths, "not only of the physical landscape but of the people who inhabit or are linked to it' (Raisborough and Adams, 2008: 10). This research explores the ways in which dominant discourses which produce The Estate as 'other' (Featherstone, 2013; Mckenzie, 2015) circulate on The Estate and are drawn upon as resources in everyday struggles for recognition. Thus, the material of estate is mediated through dominant value systems which give meaning to the structural materiality of The Estate.

\section{Methodology}

The ethnographic methodology of the research informs its focus on the 'production of everyday life' (Lather 2001: 481); the methods used (Skeggs, 2001); an analysis which connects 'meaning, social structure, power relations and history' (Lather, 2001: 481); and the textual representation of the research (Clifford and Marcuse, 1986). Through a focus on the complexity and the "becomingness" of social life, ethnography 'belies the possibility of a single, exhaustive or definitive account' (Ball, 1990: 167). Thus, the analytic approach of the research is located within the tension of deductive and inductive reasoning, re-imagining knowing as a cyclical process (MacLure, 2010). Thinking of analysis as a formative process, I understand knowledge production to be iterative; where the research object is constructed and reconstructed through the dynamic between theory and observation (Cerwonka, and Malkki, 2008). 
Fieldwork was conducted over a period of eighteen months (2013-2014) in multiple sites on The Estate, with the Community Centre and the Primary School forming two key spaces of more sustained and intensive participant observation. I gained access to the Community Centre in June 2013 and spent two days a week there until September 2014. During this time, I took on the role of 'helper' at the youth clubs and participated in both the everyday and the celebrations which marked the passing of the year at the Community Centre. In addition, I conducted fieldwork in the Primary School located on The Estate for one month in March 2014, following a Year 4 class throughout their school day. During the summer months of 2014, I conducted interviews which drew upon a range of methods as appropriate for the participant (Heyl, 2001), including; drawing and the discussion of photographs, walking conversations and semi-structured interviews.

\section{Habitus and affect}

As 'making through marking' (Skeggs, 2004: 12), classification is a felt process of becoming. It is felt as a weight on the body, in the physical reformation of inhabiting the world, and the social recognition of the differential valuing of ways of being. The habitus as felt consequence of being in the world is explored in Bourdieu's 'The Peasant and his Body' (2004). Through his account of the 'unhappy consciousness' of the bachelor who becomes 'embarrassed by his body and in his body', Bourdieu suggests a recognition of the shaping of the body by social positioning. The subjects in Bourdieu's ethnographic account come to see their bodies as 'bearing the trace of the attitudes and activities associated with peasant life' (Bourdieu, 2004: 8). Bourdieu posits that the peasant internalizes the devalued image others form of him and begins to perceive his body as an 'em-peasanted' body. This results in a break in solidarity with this image and a shift in attitude, a self-identification as 'peasant' in the pejorative sense of the word (Bourdieu, 2004: 585).

This empirical application illustrates that 'habitus can in certain instances, be built on contradictions, upon tensions, even upon instability' (Bourdieu, 1990: 116). However, the transformative potential of 
habitus appears to remain tied to material changes within the individual trajectory. Both in Bourdieu's own work and those working with and beyond conceptualisations of habitus, the generative aspects of habitus are explored through moments of material change. Theorisation of the divided or cleft habitus (Bourdieu, 2000) and the affective consequences of shifts in circumstances resulting in a habitus 'out of place' (Reay, 2007) are associated with entering an 'unfamiliar field' and the 'return of the repressed' (Reay, 2015). In these analyses, affect is the result of the 'lack of integration of the disparate experiences that make up a biography', where the divided habitus becomes marked by 'ambivalence, compromise, competing loyalties, ambiguity and conflict' (Reay, 2015: 11). Therefore, affect continues to be theoretically troubling in its connection to change. When one remains 'in-place' the affective consequences of social positioning form an aspect of the dispositions associated with a classed habitus. This may include 'a propensity to fatalism, ambivalence, resilience, certainty, entitlement or even rage' (Reay, 2015). If one experiences a shift in place, a change in material position, there are affective consequences. In both cases, affect is a product of the material position of the individual. The tying of affect to the body, and the body to its social position, anchors the affective to an imagining of the authentic self, that one is either trapped within or cleaved from.

Through a focus on the difficulty of managing movement across fields, within the context of everyday negotiations, Reay (2015) introduces a complexity to formations of habitus that begins to challenge the assumption of an authentic habitus. In her analysis of the 'struggle and conflict' experienced in the 'difficulties of reconciling white, working-class masculinities with educational success', Reay explores the affective labour associated with maintaining contradictory ways of being (Reay, 2015: 13). By bringing to the fore processes of differential valuing and devaluing experienced within the everyday, Reay alludes to the possibility for affect to be productive. Nevertheless, Reay's analysis remains tied to a stable and therefore essential sense of self. As Skeggs suggests, 'even the self produced in conditions not of its own choosing...[relies] on ideas about self interest, investment and/or "playing the game"" (Skeggs, 2011: 496). 
In the following section, I outline an alternative theorisation of habitus, in conversation with recent 'turns' towards the affective which point to the 'irredeemable sociality of any forms of self behaviour' (Skeggs and Wood, 2012: 68). I argue that through the conceptualisation of class as an 'object of belief' (Butler, 1988), post-structural thinking may enable habitus to be detangled from a stable 'I' and therefore hold open its generative capacity.

\section{Bourdieu and the post-structural}

The theoretical position of the research is informed by a post-structural questioning that begins from the premise that categorisations 'do not precede enactments but, rather, they become knowable and come alive in repetitive acts, embodied and corporeal activities' (Nayak, 2007: 7). My analysis draws upon the work of Hollingworth (2015) which conceptualises class as a performative process, that 'class is read on the body, and thus class comes to be made through these performances and readings' (Hollingworth, 2015: 4).

Thinking with Skeggs' (2004b; 2011) critique of the self as a 'classed concept', I understand the self as a consequence of classification. Therefore, the 'sociality' within which one is constituted is immersed within power dynamics; as a relational being, the 'I' is formed within moments of struggle for recognition. Therefore, the 'I' from which one may act is not a claim to a stable, unitary, autonomous viewpoint, rather as constituted in a 'sociality', 'one is always "doing” with or for another' (Butler, 2004: 1). As such, the constitution of the 'I' within sociality does not negate the reading of continuity of the self by the other. Rather, it enables a critique of this reading. It is a challenge to the notion of an essentialised being, and a bringing to the fore of the 'processes of classification: exploitation, domination, dispossession and devaluation, and their legitimation' (Skeggs, 2015: 205). 
Through a focus on process, I argue that post-structural theory may hold open the generative and agentive aspects of the habitus, thinking with the debates raised but not foreclosed in the collective works of 'Feminism after Bourdieu' (Adkins and Skeggs, 2004). By reading Bourdieu through a poststructural ontological lens, habitus may be considered performative: that which is 'put on, invariably under constraint, daily and incessantly, with anxiety and pleasure' (Butler, 1988: 531). Butler's concept of performativity centres the 'social temporality' of class, making explicit the duality of the subjective and objective within the concept of habitus. Thus, habitus may be understood as performative acts, that not only constitute the identity of the actor, but constitute that identity as a compelling illusion. This formation of class as an 'object of belief' in turn establishes the parameters of classed identity claims. Nevertheless, within the conceptualisation of habitus as performative 'resides the possibility of contesting its reified status' (1988: 520). The site of class formation then may be understood as the moment of action, the constitution of the self as a classed object through the performance of classed acts: 'a performative accomplishment compelled by social sanction and taboo' (1988: 520).

The following analysis explores moments of acting within the power dynamics of the field. Drawing on Skeggs and Wood's conceptualisation of affect as 'produced through the social encounter' (2012: 68), my analysis seeks to explore the experience of habitus formation, the felt consequences of becoming.

\section{Foregrounded history: habitus felt in the present}

As the 'active presence of past experiences' (Bourdieu, 1990: 54), habitus theorises temporality in class formation. Bourdieu's conceptualisation of habitus transcends dichotomies of individual and society locating class practice within the dialectic of 'the objectified products and the incorporated products of historical practice' (1990: 52). Habitus is therefore a process of embodiment, where 'objective potentialities [are] immediately inscribed in the present' (1990: 53), cultivating affects 
compatible with the material conditions of class: 'to refuse what is anyway denied and to will the inevitable' (1990: 54). For Bourdieu, this process of embodiment entails the 'forgetting of history', as a product of history, the habitus produces more history in accordance with the schemes generated by history. Nevertheless, habitus formation does not negate 'visceral affective reactions against one's social fate and the attempts to escape they can generate' (Lane, 2013: 3). Therefore, I suggest that rather than that which is forgotten as history, the habitus may be helpfully reconceptualised as the foregrounding of history. By drawing attention to what Bourdieu referred to as the anticipation of sanctions within habitus formation, I argue that habitus formation is felt in the everyday as a 'particularly visceral sensation' (Probyn, 2004: 3). The following analysis draws attention to moments of reflection, accounts of a lack of fit between the bodily ease of the habitus and the dominant values of particular fields.

Building upon Reay's account of the affective consequences of shifts in circumstances which result in a habitus 'out of place' (Reay, 2007; 2015); I explore the moments of negotiation that occur when one is 'in-place'. Engaging with Skeggs' critique that Bourdieu's analysis is of the making of the 'subject of value' (2011: 501), I draw upon everyday encounters of children 'in-place' in order to explore the formation of a classed habitus on The Estate. Rather than experiencing their place as though a 'fish in water' (Bourdieu and Wacquant, 1992: 127), I argue the formation of habitus is felt in the present. As affect, habitus 'intensifies and makes social divisions sensate' (Skeggs and Wood, 2012: 71). I suggest being 'in-place' captures the everyday encounters experienced within a set of interrelated fields, drawing upon data collected at two key sites of my ethnography: the Community Centre and the Primary School.

Of the two spaces, the Community Centre may more easily fit within a narrative of being 'in-place'. Founded in 1999 following the murder of a teenage boy on The Estate, a space was sought by a group of parents for the young people affected by the loss of their friend to come together. As the manager 
reflects, 'all the boys needed to be together, they didn't want to leave each other, they felt they needed to be together'. It is in this way that the Community Centre was conceptualised as their place.

The Primary school on the other hand, may be seen as a site of the reproduction of middle class culture (Bourdieu and Passeron, 1990), a field within which particular formations of self are produced and reproduced (Ingram, 2009; 2011). However, the ongoing 'diversification' of the British education system (Exley, 2012; Ball, 2016), enables the reformation of the school's ethos in light of ideas about what education is for. The Primary School was closed due to its 'failing' status and reopened as an Academy in 2013, a shift transforming conceptualisations of the school's purpose and therefore impacting pedagogical practices.

The Academies Programme, first introduced in 2002, aimed to replace schools in England located in areas of high socio-economic disadvantage with new schools independent of local government control and managed by charitable companies and governing bodies established by sponsors (National Audit Office, 2010). As an extension of broader processes of marketisation (Gewirtz, 2002), the Academies Programme facilitates the 'specialisation' of state education, contributing to a 'new politics of recognition' acting to further naturalise educational inequalities (Power and Franji, 2010: 2). The Primary School encourages its staff and pupils to be 'great by choice', locating the experiential consequences of material and structural inequality within a psychologised language of individual endeavour, leading their mission statement with the commitment that 'We won't accept excuses and we won't make excuses'. Thus, the school is not simply reproducing middle class culture, rather, through accounts of who 'these kids' are and what 'these kids' need, the school reifies an estate culture as defined through lack. In this way, I understand the school as a productive part of the children's experience of being 'in-place', rather than as 'relatively autonomous spheres of play' (Bourdieu and Wacquant, 1992: 17). 
Nevertheless, I argue both places are constituted within troubling discourses of authenticity. Through a focus on the formation of habitus in everyday moments within these inter-related fields, I aim to complicate the assumed comfort in habitus, reconceptualising habitus as the forging of the self through the co-constitution of people and place. Thus, Hall's (1996) conceptualisation of 'identification' may better capture what I assert as classed identity. Hall considers identification discursive, in that it is a 'process of articulation' (Hall, 1996: 2), never completed, actualised in the 'binding and marking of symbolic boundaries' (1996: 3). In this way identity is conceived as moments of identification:

'Throughout their careers, identities can function as points of identification and attachment only because of their capacity to exclude, to leave out, to render "outside", abjected' (Hall, 1996: 5)

Thus, as foregrounded history, habitus is moments of identification within which aspects of the self are formed in proximity and/or distance with others. This conceptualisation of relational identity construction is heavily influenced by Bourdieu's thinking, yet moves beyond habitus as 'forgotten history' (Bourdieu, 1990: 56) to habitus as 'foregrounded history'. Founded upon Skeggs' analysis of class formed within the 'moment of exchange' (Skeggs, 2004), foregrounded history is shaped within the interplay between inscription and interpretation: recognising that 'bodies are being inscribed simultaneously by different symbolic systems', yet it is only in the moment of exchange that this inscription becomes actualised as 'we learn to interpret bodies through different perspectives to which we have access' (2004: 3). Emphasising agency, foregrounded history captures the physical and psychic distancing of the self from classed inscriptions (Reay \& Lucey, 2000; 2002), considering the active construction of the self through 'carving out' (Connolly, 1995) distinct identities in processes of distancing the self from aspects of structuring discourses and appropriation. Nevertheless, an analysis of habitus as foregrounded history maintains the link between symbolic value and structural constraints, which results in some forms of culture being 'condensed and inscribed onto social groups and bodies that then mark them and restrict their movement in social space' (Skeggs, 2004: 2). 
Seeking to maintain 'fluidity of movement between units of analysis, between scales and between the particular and the general' (Thomson and McLeod, 2015: 246) habitus as foregrounded history employs a 'critical bifocality' (Weis and Fine, 2012) that explores the potentialities of agency whilst contextualising the individual actor within the material and structural conditions of social position. This theorisation of classed identity formation reflects Thomson and McLeod's (2015) call for the development of a 'processual imaginary', through the 'forging, adapting and reanimating a set of conceptual metaphors and analytic tools that help us privilege temporality' (Thomson and McLeod, 2015: 246).

\section{Disciplining the self}

In the following analysis, I argue that habitus may be shaped through the disciplining of the self; that the body is shaped by symbolic power, but that it is not simply acted upon. The foregrounding of habitus as felt in the present relocates identity formation within moments of signification (Hall, 1997). The thinking together of the momentary present and the embodied past may open analytic possibilities through a focus on agency in the formation of practice.

Friday home time, the class are a tense combination of excitement and exhaustion. Trying desperately to sit still in order to be called to retrieve their iPad for the weekend, the children seem to make strange involuntary movements, their bodies shaking with anticipation. Megan is finally called to get hers; she seems to melt with relief, relaxing for a moment in her seat before pulling herself up and walking to the far side of the classroom. She visibly tenses as she hits the back of a queue, as Linda the teaching assistant struggles to keep up with the demand of the children. 'For God's sake' mutters Megan, frustrated. Linda explodes, 'Right Megan, that's it, you will not be taking your iPad home' her voice breaks with anger, her face reddened. After a brief moment of shock, where she appears to not even take a breath, Megan begins to wail, pleading for forgiveness. She struggles to speak, between sobs and gulps of air, Megan explains 'I-can't-help-it...it-just-came-out'. She is told to sit down. 
Megan's reaction to Linda's discipline is embodied, she loses her social composure, struggles to breathe and cannot articulate her apology. The disciplining of Megan occurs within power relations; dynamic symbolic economies of value, conceptualised by Bourdieu as field (Bourdieu, 1998). An account of the relationship between habitus and field may provide some insight into why Linda perceives Megan's behaviour to be unacceptable; socially locating Megan's behaviour as a lack of the right forms of capital, a discomfort with the 'rules of the game'. However, this analysis does not consider the affective work inherent in feeling difference, understanding this difference and recognising this difference as a de-valued position. The 'forgotten history' of the habitus is foregrounded, the embodied dispositional practice encapsulated in Megan's utterance of 'For God's sake' is made visible in this moment of discipline.

This analysis makes visible a moment of change, a highlighting of difference, from which Megan's sense of self is formed. Conceptualising habitus as the foregrounding of history brings these moments of rupture into understandings of identity construction: that habitus has histories both embodied and felt in the present.

\section{Distinction/Disagreement}

Continuing this line of analysis, I now want to consider the ways in which the everyday moving between fields foregrounds habitus, making visible of differential valuing across space (Reay, 2015). In my analysis of the following extract taken from an interview with two Primary School aged children, Jack and Rosetta, I explore the interrelation of fields and argue that dominant discourses may be drawn upon as resources introducing markers which shift symbolic power within the field. 
In this moment Jack and Rosetta partake in identity work together to forge distance between their self and their positioning as Primary School pupils. The interview took place at the Community Centre, forming a dynamic within which both children had to negotiate multiple identities, that is identifications and dis-identifications, with both people and place (Skeggs, 2001). In the extract, Jack and Rosetta discuss a new teaching model, 'Performance Based Learning', where learning is performed through sing-song repetition, with key concepts represented through flamboyant actions. Such performances require a particular embodied and affective relationship with learning. Jack and Rosetta's differential ease with this highly embodied practice introduces possibilities for marking distinction (Bourdieu, 1984).

Author: I know what I was going to ask you Jack, about that Performance Based Learning, do you like that?

Jack: no, I hate it

Rosetta: it's quite easy but not that much

Author: you don't like it either?

Jack: the teachers have to say it over and over again and it keeps getting (laughs)

Rosetta: (in dramatized sing-song voice) put four in the maths table put six on the resource table, take them away, ohhh I need this (laughs)

Author: and you don't like it?

Rosetta: it's alright, it happens every day, and if we start talking we have to do it every day in play too

Jack: to practice it

Author: do you all stay in the same class to do it or do you have to move?

Rosetta: no have to change class, I have to go to year six to do it, because I'm too clever (Rosetta is in Year Three but has her maths lesson is with the middle ability Year Four group) 
Jack: no that's her learning group

Rosetta: no that's for maths and also for literacy

Jack: I'm in my normal class

Rosetta: yeah, that's the babyish class (laughs)

Jack: no, it's not

Author: how do you think they choose who goes in what class?

Rosetta: they choose who's the cleverest

Author: how do they know?

Jack: no, they don't!

Rosetta: they check our old maths see who is the best, me and my friend Annie

Jack: the goodest

Interview with Jack and Rosetta, Primary School Aged Male and Female

Jack and Rosetta utilise the social space formed by the interview to mock the 'Performance Based Learning' of the School. The Community Centre is both physically and socially distanced from the school, specifically the Performance Based Learning of the classroom. Thus, the children negotiate their position within the interview as both school pupils and Community Centre members, drawing upon the multiple and varied values and discourses of the two places to inform their construction of the practice of Performance Based Learning (Archer et al, 2007). Jack makes a joke of the repetition of his teacher, calling out the script like teaching practice: 'the teachers have to say it over and over again'. Rosetta takes this play further in an appropriation of her teacher's sing-song act, a performance which unites the children in laughter and in opposition to their in-school self. 
The distance between the children in the interview and in the classroom forms space for critical reflection, a space for performance and negotiation. This space was particularly relished by Rosetta, taking the opportunity to carve out an alternative identity, she utilises her embodied ease with Performance Based Learning to mimic her teacher; as she claims, 'it's quite easy'. In this way, the boundaries between the school and the Community Centre became blurred in the very act of discussing the Primary School within the interview. Therefore, despite a communal distancing in Jack and Rosetta's mocking of the Performance Based Learning the discussion introduced school discourses of distinction. My questioning of Jack about Performance Based Learning introduced a tension between his Community Centre self and his in-school identification, and between his experience and that of Rosetta. My introduction of school as a topic of discussion to the interview shifted the dynamic between Rosetta and Jack, enabling Rosetta to draw upon school discourses to undermine Jacks position and valorise her own within the interview. Rosetta informs me with particular glee that Jack is in the 'babyish class' and that they 'choose who's the cleverest' to go into the top classes, a group she positions herself within. Rosetta's access to school discourses of ability acts as a resource through which she positions Jack within binaries of clever/not clever, babyish/mature.

Though Rosetta constructs the foundations of her claims of distinction upon dominant school discourses of ability, Jack refuses her positioning of him. He refutes her claim that his class is 'babyish', further rejecting that groups are allocated based on ability, insisting they select who is 'goodest'. Jack disagrees with Rosetta's claims to distinction, undermining her assumed high ability, he rejects the dominant school discourse of ability, highlighting the conflation of ability with behaviour; Rosetta is not clever, she is only good.

Thus, Bourdieu's conceptualisation of distinction may be held in tension with 'mésentente', or disagreement. This conceptualisation is distinct from Bourdieu's 'méconnaisance', where symbolic 
power is exerted 'insofar as its arbitrariness is misrecognized' (Bourdieu, 1979: 83). Rather, Rancière insists upon the disputed status of speech as alliterative opposition through 'disagreement', rather than mis-knowing (Pelletier, 2012).

By introducing the disputed status of speech, Rancière (2004) considers its fragmentation in two forms; speech in its positivity and speech that is not considered speech, only noise. Thus, disagreement is:

'where there is a lack of agreement not only about the object of debate...but also the status of the speakers themselves, as speakers who speak, rather than emit noise or ventriloquize' (Pelletier, 2012: 276)

This analysis demonstrates how distinction is produced in and through struggle where fields are not tightly bounded, rather inherently relational. Although the interview was conducted within the Community Centre, dominant school discourses of ability remain powerful in the positioning of actors beyond and between the field of the school. Moving between fields foregrounds the habitus through the making visible of differential valuing of behaviour, speech and other embodied practices. The introduction of school discourses into the interview shifted the dynamic between Jack and Rosetta, enabling Rosetta to draw upon her embodied ease with school practices to challenge Jack's position within the Community Centre. Habitus as foregrounded history draws attention to temporality through an analysis of the ways 'the past and the future are always apprehended in the present' (McLeod and Thomson, 2009: 8). Thus, the affects of habitus formation are both momentary and particular (felt in the present) and constituted within historical and social contexts (structural materiality). The holding in tension of distinction (Bourdieu, 1984) and disagreement (Rancière, 2004) enables an analysis of everyday re-formations of class as a visceral encounter between the present self, embodied histories and imagined futures. As a conceptualisation of the self 'figured through the conversions of capital it can or cannot make across time and space' (Skeggs and Wood, 2012: 50), habitus anchors the self to past and future. However, the valorisation of disputed speech within everyday moments of 
disagreement may make the 'contingency of inequality sensible' (Pelletier, 2012: 274). Nevertheless, the speaking subject as performance of personhood is 'always connected to ideas about value (economic, moral, affective)' (Skeggs and Wood, 2012: 48). In the following analysis, I draw upon Skeggs' conceptualisation of personhood as property (Skeggs, 2004) to explore the processes of inscription which constitute the fixing of classed action as inaction, the misrecognition of classed speech as noise.

\section{'These kids don't play'}

'Working-class childhood is problematic because of the many ways in which it has been pathologized over the last century and a half...the children of the poor are only a measure of what they lack as children: they are a falling short of a more complicated and richly endowed "real" child' (Steedman, 1986: 127-128)

One of the things I was told about 'these kids' whilst at the school was that they 'don't play'. This was repeated to me by teachers and other staff on 'playground duty'. Play is central in representations of childhood, entwined with assumptions around childhood as a natural state of innocence and being carefree. As such, the reading of the children's behaviour as somehow other to play, requires the signification of 'these kids' as distant from representations of childhood. This process of renaming the acts of children within the school as not play involves a particular imagining of the subject, their motivations and experience of playful behaviours. The recognition of an action as play implies something about its purpose and consequences; play suspends meaning, it is distanced from necessity and everyday mundanity. Therefore, it was not that the children were not partaking in play like behaviours; rather there was something implicit in the evocation of 'these kids' by the teachers which made their play an impossibility.

The school playground was filled with the roaring noise of a contained mass, senses overloaded, sounds slip into silence. In an attempt to focus my thoughts, I look around noting the various groups of children. The majority of the playground is engulfed with a sprawling 
game of football, teams swelling well above eleven-a-side, all boys except one girl who plays each break time. Under the gazebo, commando crawling down the steps, Tommy barks orders at his 'men', visibly frustrated that they don't quite understand the rules of warfare'Obviously you die, use your nut!' Around the side of the main school building where the playground narrows into an almost private corner, I see the commotion of ongoing feuds. As if ritual, these playground fights follow the same pattern, instigated by boys, defused by girls.

I will focus on the example of a group of boys who each play time organised complex computer style army games. The teacher continually focused their claims of absent play on these boys. They were identified as 'naughty' as a group, with Tommy being seen as beyond 'bad' behaviour understood simply as absence of behaviour: he was often described as apathetic, lazy, bored, embarrassed. Yet, in play Tommy was the leader of the pack, he commanded his peers, beginning each play with a delegation of roles and an enforcement of rules. The game was an imaginary war game, based around Call of Duty, a computer game all the boys idolised whether they played it or not. Their game spread across the playground and developed a narrative across multiple play times. Their behaviour was visible to the teacher yet was not understood as play.

I think Skeggs' discussion of the 'condensing, sticking and fixing process' of identity formation is helpful here (Skeggs, 2004: 2). She talks of the embodiment of identity as a power relation. In this way some bodies may propertise their personhood, in the sense that it becomes what they possess rather than who they are. This enables them to utilise the value associated with identities, to attach and detach symbolic markers of identity to achieve relative positions of power within the field. The coming together of multiple privileges at the site of the body, endows these structurally produced bodies with the ability to do. As possession, privileged bodies are conceptualised as agentic, they are a source of power from which to act with purpose and meaning. The bodies of the structurally devalued carry the weight of their disadvantage. For the marked body, all action collapses into a 
naturalisation of bodily difference. Therefore, action is understood as inaction, as a manifestation of their being.

We may understand play in this same way, the boys' actions may be thought of as being not playing. The violence and hypermasculinity of their war game is so entangled with their embodied identity of white working class that it cannot be detached from their selves and understood as play, they just are: 'these kids don't play'.

This process of making through the marking of bodies has been most clearly articulated by Hall in his theorisation of race as a floating signifier. Hall conceptualises race as:

'a signifier which can be linked to other signifiers in a representation. Its meaning is relational and it is constantly subject to redefinition in different cultures, different moments' (Hall, 1997)

As Lentin (2008) notes, race is a system of thinking about the differences between different bodies; this difference is invoked as a signifier, and what is signified is a social position. In this way, knowledges about bodily differences we think of as 'racial' shift and change across time and space, race is therefore an ideology which creates and maintains systems of domination.

As such, conceptualising the body as a floating signifier helps us to think through the ways in which difference is read onto the body within a social context: that the body, as a site of distinction, is relationally produced and reproduced within the field. Therefore, classifications do not arise from the individual, as some essential quality of who they are, rather they come into meaning through structured relations of difference. These relations are structured in the sense that the signifying field is the coming together of dominant discourses which are historically, socially and culturally located within systems of domination. Thinking back to the example of Tommy and the warring boys, their 
raced, classed and gendered bodies act as signifiers of intangible aspects of who they are understood to be. Their bodies come to signify danger, violence, and disorder. Therefore, rather than agentic doing or playing, their behaviour becomes conflated with embodied dispositions. The boys are understood as simply inhabiting an authentic identity, lacking the requisite embodied capitals to enact play.

\section{Embarrassment as resistance}

I would like to continue this analysis by further exploring Tommy's position within the school, particularly, the difficulty with which he embodies the 'ideal learner'. I will be drawing upon Hollingworth's (2015) analysis of the ways in which the reverence of performances of white middle class identities within the education context, produces readings of some classed and raced performances and antithetical to educational success. I will explore the ways in which Tommy's 'comportment, demeanour and behaviour come to construct [him] as the impossible learner' (Hollingworth, 2015: 1241), building upon Youdell (2003) and Rollock's (2007) ethnographic work in schools where certain ways of walking or talking are viewed as confrontational.

Tommy sits heavy in his chair, his head supported by his hand, elbow on desk. His other arm hangs to his side, lifted with some effort, to mimic the movements of the Performance Based Learning. His voice rumbles in the background of the sing-song tones of the classroom. He sinks lower into his chair and sighs in exasperation.

Author's fieldnotes, $9^{\text {th }}$ March 2014

There seemed to be a significant lack of fit between the identity work Tommy invested in and valued highly, modelled on a specifically adult form of masculinity and heterosexuality, and the Performance Based Learning he experienced within the school. Engagement necessitated a rhythmic body, gentle movements and measured speech patterns. Mirroring the teacher, the children perform sentences; each word assigned a gesture, each said in slow, soft, musical tones. Tommy's overtly adult, masculine identity work is necessarily in opposition to this. He refuses to participate in the body management 
required, he does not soften his voice to sing his response; he joins in with monotone, truncated speech. He does not keep up with the flow of arm gestures, his body appears heavy, lacking the embodied readiness required for learning within the context.

Tommy is distanced from the Performance Based Learning of the school and this distancing is entangled with affect; Tommy's embarrassment of Performance Based Learning is both a consequence and a response to his positioning. Thus, embarrassment becomes an affective position from which Tommy may form his identity. His embarrassment of school activities, from Performance Based Learning in the classroom to singing in assemblies, is a tool with which he carves out his masculine adult identity in opposition to the assumed childhoods of 'school children'.

Nevertheless, Tommy's resistance is necessarily contradictory. Though his embarrassed performance may reassert his position amongst his peers, this very performance feeds into his de-valuing. Tommy's distance from Performance Based Learning is understood as a distance from childhood itself. His apparent rejection of childhood identity work means that his behaviour can only be known as lack; childhood as with all classification is connected to the body; the body and behaviour are often conflated, thus in moments where body and behaviour contradict, action is read as non-action. Tommy's investment in masculine adult behaviours cannot be made 'sensible' when read with his child body, therefore, this behaviour may only be conceived of in the negative: as the absence of child behaviour and the capacity to learn 'properly'.

\section{Conclusion}

In conclusion, the re-conceptualisation of habitus as foregrounded history outlined in this paper, may act as an analytic tool in the exploration of the process of class formation and the role of the affective in both its production and reproduction. As embodied, habitus is formed through affect; it is made in moments where social divisions become sensate (Skeggs and Wood, 2012: 71). The experiential of 
the 'making through marking' (Skeggs, 2004) of class is formative of the self. In conversation with Skeggs' critique of the self as a classed concept (Skeggs, 2011), this paper argued that a poststructural theorisation of the constitution of the 'I' within 'sociality' (Butler, 2004: 1), may hold open the generative space within theorisations of habitus. Skeggs' cautions that a theoretical gaze informed through 'abstractions from the bourgeois model of singular self' may obscure 'how value is produced and lived beyond the dominant symbolic' (Skeggs, 2011: 509). Through an analysis of the everyday encounters of children on The Estate I have explored 'alternative, lived and emplaced practices' (2011: 508), arguing that these self-formations are never 'beyond' the dominant symbolic, rather are constituted in moments of encounter with and against it. Drawing upon Rancière (2004), my analysis sought to valorise the formation of self on The Estate through an account of moments which 'transgress the boundaries of categories' (Pelletier, 2012: 274).

Inspired by Skeggs' questioning of how 'people inhabit personhood when they are positioned as the constitutive limit of it' (2011; 503), I suggest that an analysis of habitus as foregrounded history may draw attention to the everyday consequences of structural inequality whilst maintaining an ethical commitment to representing participants in their lived complexity. I am compelled by Skeggs' account of 'imagining personhood differently' (2011); however, I argue formations of the classed self are forged within encounters with the dominant symbolic and it is this moment which forms the site of class production, reproduction and resistance.

\section{Bibliography}

Adkins, L. \& Skeggs, B. (2004). Feminism After Bourdieu, Oxford: Blackwell.

Atkinson, W., Roberts, S. \& Savage, M. eds. (2012). Class Inequality in Austerity Britain: Power, Difference and Suffering. Palgrave Macmillan.

Archer, L., Halsall, A., \& Hollingworth, S. (2007). 'Class, Gender, (Hetero)Sexuality and Schooling: Paradoxes within Working-Class Girls Engagement with Education and Post-16 Aspirations', British Journal of Sociology of Education, 28(2), pp. 165-180.

Back, L. (2007). The Art of Listening. Oxford: Berg. 
Ball, S.J. (1990). Self-doubt and soft data: social and technical trajectories in ethnographic fieldwork. International Journal of Qualitative Studies in Education, 3(2), pp.157-171.

Ball, S.J. (2016). Education, Justice and Democracy: The Struggle Over Ignorance and Opportunity. In Reimagining the Purpose of Schools and Educational Organisations. pp. 189-205. Switzerland: Springer International Publishing.

Bhabha, H. K. (1996). 'Cultures in Between' in Questions of Cultural Identity. Hall, S. and Du Gay, P. London, Sage Publications.

Bourdieu, P. (1977). Outline of a Theory of Practice. Cambridge University Press.

Bourdieu, P. (1979). Symbolic power. Critique of anthropology, 4(13-14), pp.77-85.

Bourdieu, P. (1980). The Logic of Practice. Stanford University Press, California.

Bourdieu, P. (1983). The Forms of Capital in Ball, S. (ed) (2004). The RoutledgeFalmer Reader in Sociology of Education. London: RoutledgeFalmer.

Bourdieu, P. (1990). The Logic of Practice. Cambridge: Polity.

Bourdieu, P. (2000). Pascalian meditations. Cambridge: Polity Press.

Bourdieu, P. (2004). 'The Peasant and His Body'. Ethnography, 5(4), pp. 579-599.

Bourdieu, P. (2005). Habitus in Hillier, J. and Rooksby, E. eds. (2005). Habitus: A Sense of Place. Aldershot: Ashgate Publishing Company.

Bourdieu, P. \& Passeron, J.C. (1990). Reproduction in Education, Society and Culture (Vol. 4). London: Sage.

Bourdieu, P. \& Wacquant, L.J. (1992). An Invitation to Reflexive Sociology. Cambridge: Polity Press.

Butler, J. (1988). 'Performative Acts and Gender Constitution: An Essay in Phenomenology and Feminist Theory. Theatre Journal, 40(4), pp. 519-531.

Butler, J. (1990). Gender trouble: Feminism and the Subversion of Identity. New York; London: Routledge.

Butler, J. (2004). Undoing gender. New York; London: Routledge.

Cerwonka, A. \& Malkki, L.H. (2008). Improvising Theory: Process and Temporality in Ethnographic Fieldwork. University of Chicago Press.

Clifford, J. \& Marcus, G.E. (1986). Writing Culture: The Poetics and Politics of Ethnography. Berkeley, California; London: University of California Press.

Elkind, D. (2007). The Hurried Child: Growing up too Fast too Soon. Da Capo Press.

Exley, S. (2012). 'The Politics of Educational Policy Making Under New Labour: An Illustration of Shifts in Public Service Governance', Policy \& Politics, 40(2), pp. 227-244.

Gewirtz, S. (2002). The Managerial School: Post-Welfarism and Social Justice in Education. London: Routledge.

Hall, S. (1997). Race: The Floating Signifier. Media Education Foundation.

Hanley, L. (2007). Estates: An Intimate History. London: Granta. 
Heyl, B.S. (2001). Ethnographic Interviewing. In Atkinson, P., Coffey, A., Delamont, S., Lofland, J. and Lofland, L. (eds.), Handbook of Ethnography. Sage.

Hollingworth, S. (2015). 'Performances of Social Class, Race and Gender Through Youth Subculture: Putting Structure Back in to Youth Subcultural Studies', Journal of Youth Studies, 18(10), pp. 1237-1256.

Ingram, N. (2009). 'Working-Class Boys, Educational Success and the Misrecognition of WorkingClass Culture', British Journal of Sociology of Education, 30(4), pp. 421-434.

Ingram, N. (2011). 'Within School and Beyond the Gate: The Complexities of Being Educationally Successful and Working Class', Sociology, 45(2), pp. 287-302.

Jensen, T. (2014). 'Welfare Commonsense, Poverty Porn and Doxosophy'. Sociological Research Online, 19(3).

Lane, J.F. (2012). 'From “Amor Fati” to "Disgust": Affect, Habitus, and Class Identity in Didier Eribon's Retour à Reims', French Cultural Studies, 23(2), pp. 127-140.

Lather, P. (2001). Postmodernism, Post-Structuralism and Post (Critical) Ethnography: Of Ruins, Aporias and Angels, in Atkinson, P., Coffey, A., Delamont, S., Lofland, J. and Lofland, L. eds. (2001). Handbook of ethnography. Sage.

Lentin, A. (2008). Racism: A Beginner's Guide. Oxford: Oneworld Publications.

Lucey, H. (2010). 'Sisters' Stories: A Psychosocial Perspective on Families, Peers and Social Class in Resistance and Conformity to Education', Gender and Education, 22(4), pp. 447-462.

McLeod, J. \& Thomson, R. (2009). Researching Social Change: Qualitative Approaches. Sage: London.

MacLure, M. (2013). 'The Wonder of Data', Cultural Studies $\leftrightarrow$ Critical Methodologies, 13(4), pp. 228-232.

Mckenzie, L. (2015). Getting By: Estates, Class and Culture in Austerity Britain. Policy Press.

Meisenhelder, T. (2006). 'From Character to Habitus in Sociology', The Social Science Journal, 43(1), pp. 55-66.

National Audit Office. (2010). The Academies Programme. Ireland: The Stationary Office.

Nayak, A. (2007). 'Critical Whiteness Studies', Sociology Compass, 1(2), pp. 737-755.

Nayak, A. (2011). 'Geography, Race and Emotions: Social and Cultural Intersections', Social \& Cultural Geography, 12(6), pp. 548-562.

Power, S. \& Frandji, D. (2010). 'Education Markets, the New Politics of Recognition and the Increasing Fatalism Towards Inequality'. Journal of Education Policy, 25(3), pp. 385-396.

Probyn, E. (2004). 'Everyday Shame', Cultural Studies, 18(2-3), pp. 328-349.

Raisborough, J. \& Adams, M. (2008) 'Mockery and Morality in Popular Cultural Representations of the White, Working Class', Sociological Research Online, 13(6).

Rancière, J. (2004). Disagreement: Politics and philosophy. University of Minnesota Press.

Reay, D. (2000). Children's Urban Landscapes: Configurations of Class and Place, pp.151-164 in Munt, S. eds. (2000). Cultural Studies and the Working Class: Subject to Change. Cassell, London and New York. 
Reay, D. (2004). “"It's All Becoming a Habitus": Beyond the Habitual use of Habitus in Educational Research', British Journal of Sociology of Education, 25(4), pp. 431-444.

Reay, D. (2007). 'Unruly Places: Inner-city Comprehensives, Middle-class Imaginaries and Workingclass Children', Urban Studies Special Issue on The Geography of Education, 44(7), pp. 11911203.

Reay, D. (2015). 'Habitus and the Psychosocial: Bourdieu with Feelings', Cambridge Journal of Education, 45(1), pp. 9-23.

Reed-Danahay, D. (2005). Locating Bourdieu. Bloomington: Indiana University Press.

Rooke, A. \& Gidley, B. (2010). Asdatown: The Intersections of Classed Places and Identities in Taylor, Y. (ed). Classed Intersections: Spaces, Selves, Knowledges. Farnham: Ashgate.

Rollock, N. (2007). 'Legitimizing Black Academic Failure: Deconstructing Staff Discourses on Academic Success, Appearance and Behaviour', International Studies in Sociology of Education, 17(3), pp. 275-287.

Skeggs, B. (2004). Class, Self, Culture. London: Routledge.

Skeggs, B. (2004b), 'Exchange Value and Affect: Bourdieu and the Self'. in Adkins, L. and Skeggs, B. Feminism After Bourdieu, Oxford: Blackwell.

Skeggs, B. (2011). 'Imagining Personhood Differently: Person Value and Autonomist Working-Class Value Practices', The Sociological Review, 59(3), pp. 496-513.

Skeggs, B. (2015). 'Introduction: Stratification or Exploitation, Domination, Dispossession and Devaluation?', The Sociological Review, 63(2), pp. 205-222.

Skeggs, B. \& Wood, H. (2012). Reacting to Reality Television: Performance, Audience and Value. Routledge.

Steedman, C. (1986). Landscape for a Good Woman: A Story of Two Women. London: Virago Press.

Thomson, R. \& McLeod, J. (2015). 'New Frontiers in Qualitative Longitudinal Research: An Agenda for Research', International Journal of Social Research Methodology, 18:3, 243-250.

Walkerdine, V. (2010). 'Communal Beingness and Affect. An Exploration of Trauma in an ExIndustrial Community', Body and Society, 16(1), pp. 91-116.

Youdell, D. (2003). 'Identity Traps or How Black Students Fail: The Interactions Between Biographical, Sub-Cultural, and Learner Identities', British Journal of Sociology of Education, 24(1), pp. 3-20. 